\title{
PENGARUH MODEL PEMBELAJARAN KOOPERATIF DENGAN BANTUAN MEDIA TULANG NAPIER TERHADAP HASIL BELAJAR MATEMATIKA SISWA KELAS III SD IT DINIYAH PEKANBARU
}

\author{
Wulan Winanda ${ }^{1}$, Zetra Hainul Putra ${ }^{1^{*}}$, Zufriady ${ }^{1}$ \\ ${ }^{1}$ Program Studi Pendidikan Guru Sekolah Dasar,
}

Fakultas Keguruan dan IImu Pendidikan, Universitas Riau, Pekanbaru, Indonesia zetra.hainul.putra@lecturer.unri.ac.id

Received: March $08^{\text {th }}, 2020$

Revised: August $18^{\text {th }}, 2020$

Accepted: August $20^{\text {th }}, 2020$

\begin{abstract}
The background of this research is less active students in the learning process. This study aims to determine the effect of cooperative learning models with the help of Napier bone media on mathematics learning outcomes in multiplication operations of third grade students at SD IT Diniyah Pekanbaru. The subjects of this study were 21 third grade students. The method in this study was preexperimental using one group pretest posttest design. In this study data were collected using tests that were the initial test (pretest) and the final test (posttest). Based on the results of the hypothesis test obtained t_count $=15.9609 \geq t_{-}$table $=$ 1.7247. It can be concluded that there is an effect of applying cooperative learning models with the help of Napier bone media on mathematics learning outcomes in multiplication operations of third grade students of SD IT Diniyah Pekanbaru.
\end{abstract}

Keyword: cooperative learning models; learning results; Napier bone media.

\section{PENDAHULUAN}

Belajar merupakan proses internal yang kompleks meliputi ranah kognitif, afektif dan juga psikomotorik. Proses belajar terlihat dari perilaku siswa ketika proses belajar mengajar berlangsung. Perilaku belajar siswa merupakan respon siswa terhadap tindakan mengajar atau tindakan pembelajaran dari guru (Aunurrahman, 2014). Tugas utama seorang guru yaitu merancang kegiatan pembelajaran termasuk metode, model, strategi pembalajaran serta media pembelajaran dan instrumen lain yang dapat meningkatkan kualitas pembelajaran yang akhirnya dapat meningkatkan hasil belajar siswa. Metode mengajar konvensional yang proses pembelajarannya masih berpusat kepada guru dengan cara berceramah atau bercerita dan siswa mendengarkan penjelasan tersebut masih belum mampu mengoptimalkan potensi siswa dalam belajar. Namun, pada proses pembelajaran saat ini proses belajar mengajar harus kreatif dan inovatif 
melalui penerapan model pembelajaran dan juga penggunaan media yang dapat memudahkan siswa memahami materi yang diberikan oleh guru. Sebagai contoh, Putra dkk (2011) menggunakan media boneka tangan dalam mendukung siswa kelas satu sekolah dasar meningkatkan kemampuan kombinasi bilangan 10.

Kenyataan di SD IT Diniyah Pekanbaru, guru masih menggunakan metode konvensional yang membuat siswa kurang aktif dan bersemangat dalam proses pembelajaran dan ada beberapa anak yang kurang menyukai pelajaran matematika karena dianggap sulit dan menakutkan. Berkaitan dengan persoalan tersebut perlu kiranya dirancang pembelajaran matematika menggunakan model pembelajaran serta media pembelajaran yang dapat menarik perhatian siswa dan dapat melibatkan siswa secara aktif dalam proses pembelajaran serta siswa juga dapat memahami materi yang ada dalam pelajaran matematika.

Salah satunya dapat menerapkan model pembelajaran kooperatif karena model pembelajaran ini melibatkan siswa untuk saling membantu satu dengan yang lain dalam menyelesaikan persoalan yang diberikan melalui kelompokkelompok kecil yang beranggota 4-6 siswa (Delpika dkk, 2019; Guslinda \& Witri, 2018; Lazim dkk, 2018, Marhadi dkk, 2018). Tidak hanya dapat menggunakan model pembelajaran agar siswa menjadi lebih aktif karena dapat juga menggunakan media untuk lebih menarik perhatian siswa. Media pembelajaran merupakan sebuah alat peraga yang dapat digunakan pendidik dalam menyampaikan informasi kepada siswa agar sesuai dengan tujuan yang diharapkan

\section{MODEL PEMBELAJARAN KOOPERATIF DAN MEDIA TULANG NAPIER}

Model pembelajaran adalah rancangan yang digunakan sebagai panduan dalam merencanakan dan menyusun pembelajaran di kelas (Suprijono, 2015). Model pembelajaran berkaitan erat dengan pendekatan yang akan digunakan. Model pembelajaran memuat tujuan pembelajaran, tahap-tahap kegiatan pembelajaran, pengelolaan kelas, dan lingkungan pembelajaran. Model pembelajaran yang tepat dapat membantu guru dalam menyampaikan informasi kepada peserta didik dalam proses pembelajaran. 
Ada beberapa model pembelajaran diantaranya model pembelajaran kooperatif. Model pembelajaran kooperatif merupakan model pembelajaran yang menuntut siswa belajar dalam kelompok kecil yang beranggotakan 4-6 orang. Karakter peserta didik dalam kelompok tersebut yaitu bersifat heterogen (Rusman, 2016). Sejalan dengan itu, Daryanto dan Rahardjo (2012) mengungkapkan bahwa

"Model pembelajaran kooperatif merupakan suatu model pembelajaran yang mengutamakan adanya kelompok-kelompok kecil, siswa yang berada dalam kelompok mempunyai kemampuan yang berbeda-beda dan model pembelajaran kooperatif mengutamakan kerja sama dalam menyelesaikan suatu permasalahan untuk mencapai suatu tujuan yang telah ditentukan."

Menurut Slavin (dalam Daryanto dan Rahardjo, 2012:243) sintak atau langkah-langkah dalam model pembelajaraan kooperatif terdiri dari 6 fase atau tahapan yaitu menyampaikan tujuan dan mempersiapkan siswa, menyajikan informasi, mengorganisir siswa kedalam kelompok-kelompok bekerja dan belajar, evalusi dan memberikan penghargaan.

Media pembelajaran dapat diartikan sebagai alat yang digunakan untuk menyampaikan materi pembelajaran (Gagne dan Brigss dalam Arsyad, 2002). Napier (dalam Sundayana, 2015) yang merupakan seorang ahli matematika menemukan logaritma, atau alat yang dapat membantu siswa mencari hasil kali yang dinamakan tulang Napier (Gambar 1). Media tulang Napier dapat digunakan dalam perkalian dimana bilangan yang mengalikan terletak pada batang indeks dan bilangan yang dikalikan terletak pada kepala-kepala tulang. Hasil perkalian terbagi menjadi dua bagian yaitu bagian atas yang menunjukkan puluhan dan bagian bawah menunjukkan satuan.

\begin{tabular}{|l|l|l|l|l|l|l|l|l|l|l|}
\hline Indeks & 0 & 1 & 2 & 3 & 4 & 5 & 6 & 7 & 8 & 9 \\
\hline
\end{tabular}




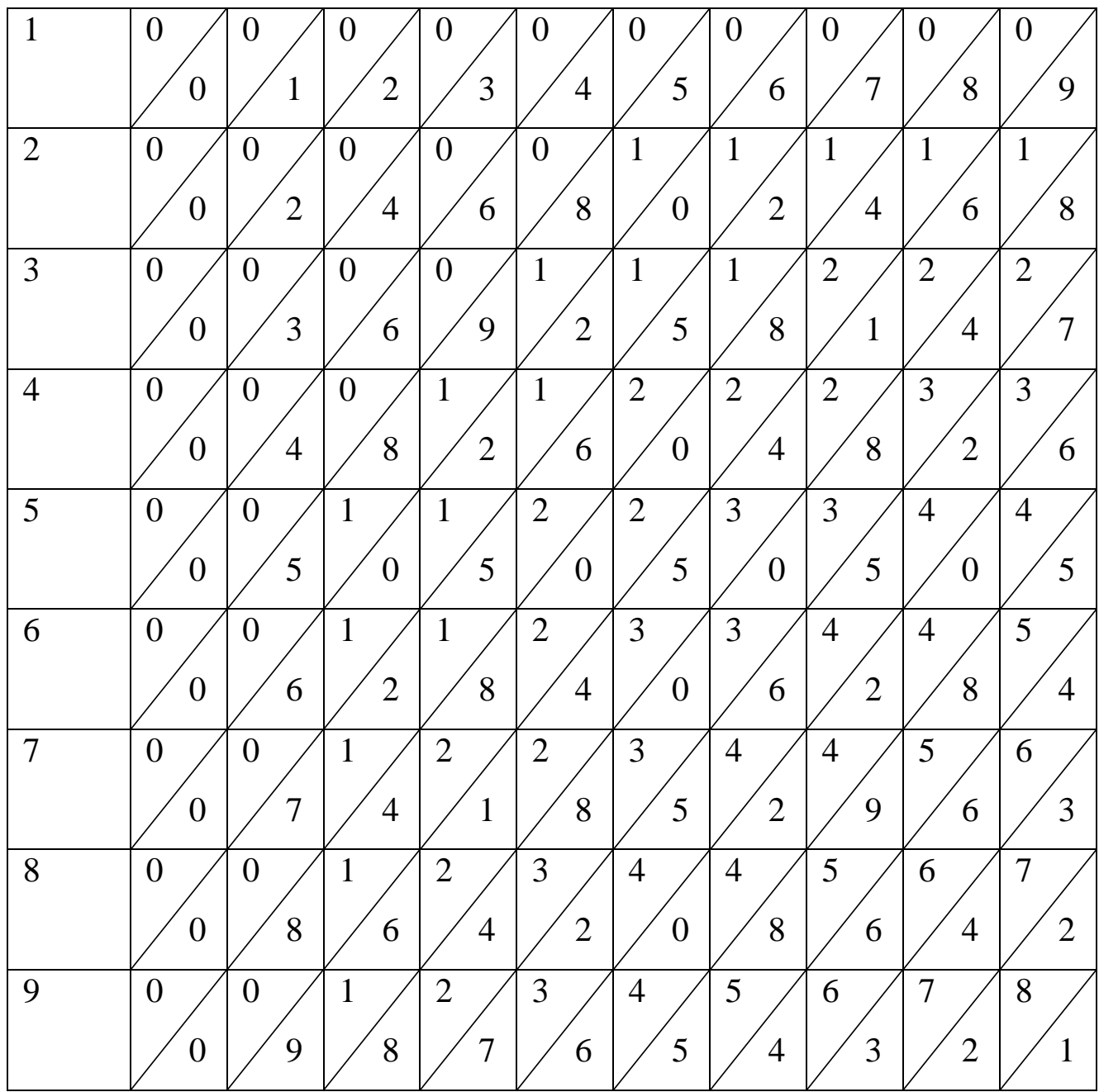

Gambar 1. Media tulang Napier

Adapun cara penggunaan media tulang napier diuraikan dengan mengambil contoh perkalian $58 \times 47$.

a. Angka 58 dipisah menjadi angka 5 ditulis dibaris satu kolom dua dan angka 8 ditulis dibaris satu kolom 3 sedangkan angka 47 dipisah menjadi angka4 ditulis dibaris dua kolom empat dan angka 7 ditulis dibaris tiga kolom empat, yang terpenting penulisan tidak boleh salah posisi dari $X$ (tanda operasi hitung perkalian)

Berikut ini cara mengerjakannya:

Langkah 1: 


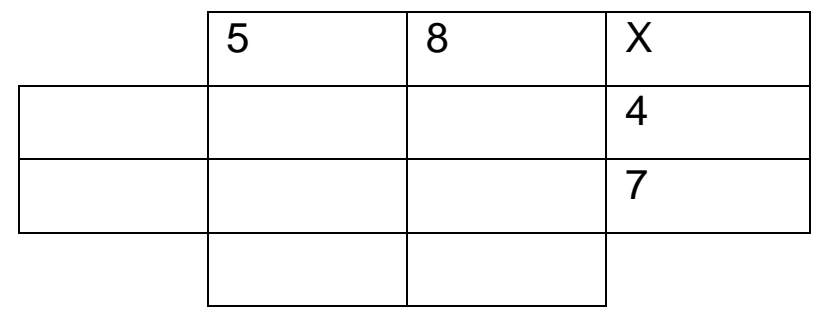

Langkah 2:

Isi kolom dengan hasil perkalian bilangan yang akan dikalikan sesuai dengan kolomnya masing-masing dan diletakan terpisah secara diagonal dimana angka puluhan ditulis diatas garis diagonal dan satuan ditulis dibawah garis diagonal

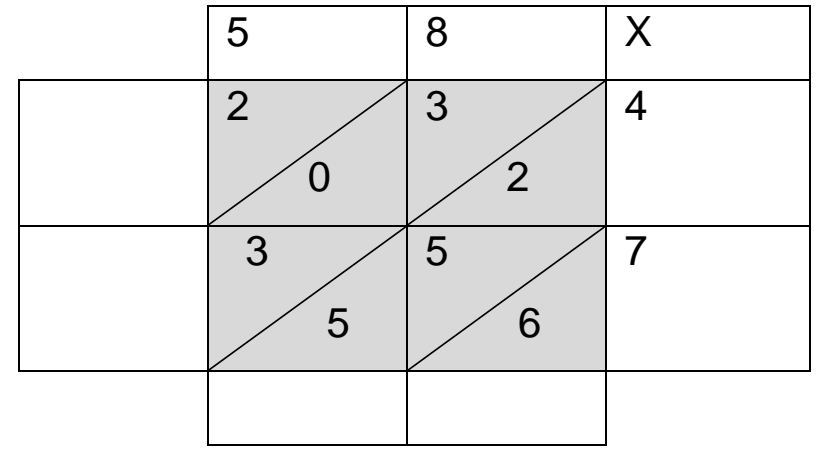

Langkah 3:

Jumlahkan secara diagonal hasil yang sudah dikalikan dan diletakkan pada kolom hasil

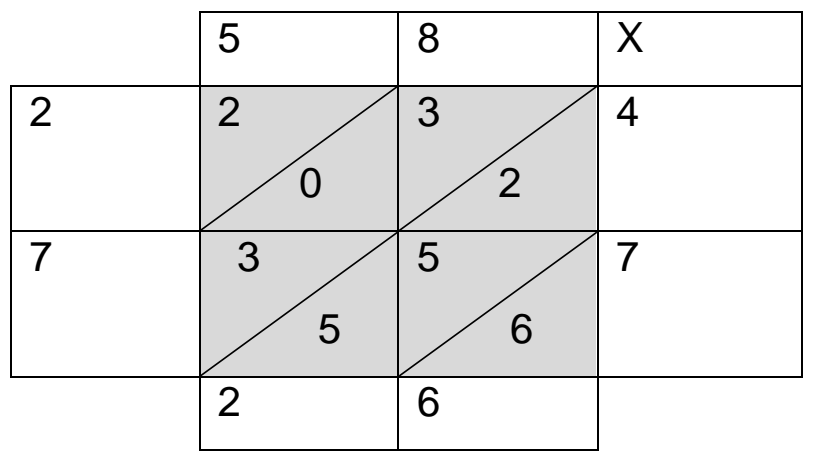

Jadi hasil perkalian $58 \times 47$ adalah 2726

\section{METODE PENELITIAN}


Penelitian ini menggunakan desain pre-eksperimen yaitu penelitian yang bertujuan untuk melihat pengaruh perlakuan tertentu terhadap suatu subjek atau objek dalam kondisi yang terkendalikan. Penelitian ini menggunakan desain one group pretest posttest design. Dalam penelitian ini terlebih dahulu sampel diberi test awal (pretest) kemudian diberi perlakukan (treatment) dan selanjutnya diberi test akhir (posttest). Tujuan dari pemberian tes yaitu untuk membandingkan antara keadaan subjek sebelum diberi perlakuan dengan sesudah diberi perlakuan (Sugiono,2017:10)

Subjek penelitian ini adalah 21 siswa siswa kelas III SD IT Diniyah Pekanbaru. Siswa tersebut terdiri dari 10 siswa laki-laki dan 11 siswa perempuan. Tes yang dibuat berupa soal objektif dengan empat alternatif jawaban. Soal yang diberikan pada tes awal sama dengan soal yang diberikan pada tes akhir. Uji normalitas dilakukan untuk mengetahui apakah data tersebut berdistribusi normat atau tidak. Uji normalitas yang digunakan yaitu uji kolmogrov-smirnov dengan perumusan hipotesis sebagai berikut:

Jika $a_{\text {max }}>D_{\text {tabel }}$ maka $H_{0}$ ditolak

Jika $a_{\text {max }}<D_{\text {tabel }}$ maka $H_{0}$ diterima

Tabel 1. Hasil uji normalitas data

\begin{tabular}{ccccc}
\hline Tes & $\mathrm{N}$ & $\begin{array}{c}\text { Normalitas } \\
a_{\max }\end{array}$ & $D_{\text {tabel }}$ & Keputusan \\
& \multicolumn{5}{c}{0,1788} & 0,2967 & Normal \\
\hline Awal (Pretest) & 21 & 0,1984 & 0,2967 & Normal \\
\hline Akhir & 21 & & \\
(Posttest) & \multicolumn{5}{c}{} \\
\hline Berdasarkan tabel 1 dapat diketahui bahwa skor awal (posttest) yaitu $a_{\text {max }}$
\end{tabular}

$0,1788<D_{\text {tabel }} 0,2967$ sehingga data berdistribusi normal. Skor akhir (posttest) yaitu $a_{\max } 0,1984<D_{\text {tabel }} 0,2967$ sehingga berdistribusi normal.

\section{HASIL PENELITIAN}


Hasil penelitian terdiri dari peningkatan skor hasil belajar antara pretest dan posttest serta mengetahui ada atau tidaknya perbedaan signifikan antara skor rata-rata tes awal (pretest) dan skor rata-rata tes akhir (posttest) dengan menerapkan model pembelajaran kooperatif dengan bantuan media tulang napier.

\section{N-Gain}

$\mathrm{N}$-Gain digunakan untuk mengetahui besarnya peningkatan hasil belajar matematika sebelum dan sesudah diberikan tindakan dengan menarapkan model pembelajaran kooperatif dengan bantuan media tulang Napier. Tabel 2 menyajikan besarnya peningkatan hasil belajar siswa tersebut.

Tabel 2. Peningkatan hasil belajar siswa

\begin{tabular}{lllll} 
& $\mathrm{N}$ & Pretest & Posttest & Gain \\
\hline Jumlah & 21 & 1359,6 & 1825,6 & 14,11 \\
\hline Rata-rata & & 64,74 & 86,93 & 0,67 \\
\hline
\end{tabular}

Berdasarkan tabel 2 diketahui bahwa terdapat peningkatan hasil belajar siswa dari pretest ke posttest. Rata-rata skor pretest siswa yaitu 64,74 dan setelah diberikan tindakan dengan menerapkan model pembelajaran kooperatif dengan bantuan media tulang napier meningkat pada posttest yaitu 86,93. Adapun N-Gain hasil belajar siswa berjumlah 14,11 dengan rata-rata 0,67 termasuk pada kategori sedang.

\section{Uji Beda Pretest dan Posttest}

Uji ini dilakukan untuk melihat adanya signifikansi perbedaan antara skor rata-rata pada tes awal (posttest) dengan skor rata-rata pada tes akhir (posttest) dengan hipotesis sebagai berikut:

$$
\begin{aligned}
& \text { Tolak } H_{0} \text { jika } t_{\text {hitung }}>t_{\text {tabel }} \\
& \text { Terima } H_{0} \text { jika } t_{\text {hitung }}<t_{\text {tabel }}
\end{aligned}
$$

Artinya :

Tolak $H_{0}$ : terdapat peningkatan hasil belajar matematika siswa kelas III SD IT Diniyah Pekanbaru yang signifikan antara hasil sebelum (pretest) dan 
hasil sesudah (posttest) dengan menerapkan model pembelajaran kooperatif dengan bantuan media tulang napier.

Terima $H_{0}$ : tidak terdapat peningkatan hasil belajar matematika siswa kelas III SD

IT Diniyah Pekanbaru yang signifikan antara hasil sebelum (pretest) dan hasil sesudah (posttest) dengan menerapkan model pembelajaran kooperatif dengan bantuan media tulang napier.

Tabel 3. Uji beda rata-rata

\begin{tabular}{rcrrrll}
\hline $\mathrm{N}$ & $M_{d}$ & $\sum x d^{2}$ & $t_{\text {tabel }}$ & $t_{\text {hitung }}$ & Hipotesis & Kesimpulan \\
\hline 21 & 22,1905 & 811,96 & 1,7247 & 15,9609 & Tolak & Signifikan \\
\hline
\end{tabular}

Berdasarkan tabel 3 dapat diketahui bahwa $t_{\text {hitung }} 15,9609>t_{\text {tabel }} 1,7247$ maka tolak $H_{0}$ artinya signifikan. Ini berarti terdapat peningkatan hasil belajar matematika siswa kelas III B SD IT Diniyah Pekanbaru yang signifikan setelah menerapkan model pembelajaran kooperatif dengan bantuan media tulang Napier.

\section{PEMBAHASAN}

Penelitian ini menggunakan model pembelajaran kooperatif dengan bantuan media tulang napier. Data yang diperoleh dalam penelitian ini adalah data hasi tes awal, hasil tes akhir, peningkatan skor hasil belajar siswa. Penelitian ini betujuan untuk mengetahui adanya pengaruh model pembelajaran kooperatif dengan bantuan media tulang Napier terhadap hasil belajar matematika siswa.

Hasill analisis terhadap skor peningkatan nilai soal pretest siswa adalah 64,74 menjadi 86,93 pada soal posttest, dan diperoleh rata-rata gain skor sebesar 0,67 berkategori sedang dan berdasarkan analisis uji t diperoleh t_hitung15,9609 $>$ t_tabel 1,7247 maka tolak $\mathrm{H} \_0$ artinya signifikan berarti terdapat pengaruh model pembelajaran koopertif dengan bantuan media tulang napier terhadap hasil belajar matematika siswa. Sejalan dengan Linda (2014) yaitu terdapat pengaruh penggunaan media tulang napier tehadap pemahaman konsep perkalian siswa kelas III Sekolah Dasar di Pamulung, dan juga sejalan dengan penelitian Sari 
(2018) yaitu terdapat pengaruh penggunaan media tulang napier terhadap hasil belajar matematika di kelas III Madrasah Ibtidaiyah di Bandar Lampung.

Model pembelajaran kooperatif dengan bantuan media tulang Napier dalam penelitian ini mampu meningkatkan hasil belajar matematika siswa karena menjadikan siswa lebih aktif belajar didalam kelompok dan siswa belajar menghargai pendapat orang lain untuk menyelesaikan sebuah permasalahan. Hal yang sama dinyatakan oleh Daryanto dan Rahardjo (2012) bahwa

"Model pembelajaran kooperatif merupakan model pembelajaran yang mengutamakan adanya kelompok-kelompok, siswa yang berbeda dalam kelompok mempunyai kemampuan yang berbeda-beda dan model pembelajaran kooperatif mengutamakan kerja sama dalam menyelesaikan suatu permasalahan untuk mencapai suatu tujuan yang telah ditentukan."

Belajar menggunakan media dapat membuat siswa menjadi aktif dan lebih tertarik untuk mengikuti proses pembelajaran dan dengan menggunakan media pembelajaran guru lebih mudah untuk mencapai tujuan pembelajaran. Hal yang sama dinyatakan oleh Hamalik (dalam Arsyad, 2002) bahwa komunikasi dapat berjalan dengan lancar apabila menggunakan media pembelajaran. Sedangkan media tulang napier dapat membantu siswa dalam menyelesaikan soal-soal perkalian dimana langkah-langkah pengerjaannya mudah dipahami yaitu bilangan yang mengalikan terletak pada batang indeks dan bilangan yang dikalikan terletak pada kepala-kepala tulang, dari hasil perkalian tersebut terbagi menjadi dua bagian, bagian atas menunjukkan puluhan dan pada bagian bawah menunjukkan satuan dan proses akhirnya menjumlahkan angka-angka tersebut secara diagonal. Oleh karena itu proses pembelajaran dengan menerapkan model pembelajaran kooperatif dengan bantuan media tulang napier dapat membuat kegiatan proses pembelajaran lebih aktif dan menarik perhatian siswa dan dapat meningkatkan hasil belajar siswa.

\section{SIMPULAN}


Berdasarkan hasil analisis data dan pembahasan yang telah dilakukan dapat disimpulkan bahwa terhadap pengaruh yang signifikan antara model pembelajaran kooperatif dengan bantuan media tulang napier terhadap hasil belajar matematika siswa kelas III SD IT Diniyah Pekanbaru dengan materi operasi bilangan perkalian. Hal ini ditunjukkan dari peningkatan rata-rata hasil belajar siswa pada tes awal yang mendapatkan rata-rata 64,74 menjadi 86,93 pada tes akhir terdapat perbedaan peningkatan hasil belajar matematika siswa dengan menggunakan model pembelajaran kooperatif dengan bantuan media tulang napier sebesar 14,11 dengan rata-rata 0,67 berkategori sedang artinya penggunaan model pembelajaran kooperatif dengan bantuan media tulang napier dapat meningkatkan hasil belajar matematika dan berdasarkan analisis uji t diperoleh t_hitung15,9609 >t_tabel 1,7247 maka tolak H_o artinya signifikan berarti terdapat pengaruh model pembelajaran koopertif dengan bantuan media tulang napier terhadap hasil belajar matematika siswa.

\section{DAFTAR PUSTAKA}

Arsyad, A. (2002). Media Pembelajaran. Jakarta: PT Raja Grafindo Persada.

Aunurrahman. (2014). Belajardan Pembelajaran. Bandung: Alva Beta CV.

Daryanto \& Rahardjo, M. (2012). Model Pembelajaran Inovatif. Yogyakarta: Gava Media.

Delpika, D. dkk. (2019). Penerapan model pembelajaran kooperatif tipe make and match untuk meningkatkan hasil belajar IPA siswa kelas IIIA SD Negeri 191 Pekanbaru. Tunjuk Ajar: Jurnal Penelitian Ilmu Pendidikan, 2(2), 123-133.

Desmita. (2014). Psikologi Perkembangan Peserta Didik. Bandung: PT Remaja Rosdakarya

Guslinda, G., \& Witri, G. (2018). Penerapan model pembelajaran kooperatif tipe make and match untuk meningkatkan hasil belajar IPS siswa. Tunjuk Ajar: Jurnal Penelitian Ilmu Pendidikan, 1(1), 1-13.

Lazim, N. dkk. (2018). Utilizing Cooperative Learning Model Types Make a Match toPromote Primary Students' Achivement in Science. Journal of Teaching and Learning in Elementary Education, 1(1), 11-19.

Linda. (2014). Pengaruh Penggunaan Alat Peraga Batang Napier Terhadap Pemahaman Konsep Perkalian Siswa Kelas III SD Muhammadiyah 12 Pamulung. Universitas Islam Negeri Syarif Hidyatullah Jakarta.

Marhadi, H. dkk. (2018). Effect of Cooperative Learning Model Type Course Review Horay $(\mathrm{CRH})$ on Elementary Students' Learning Outcome in Social 
Subject. Journal of Teaching and Learning in Elementary Education, 1(1), 20-29.

Putra, Z. H., Darmawijoyo, D., Putri, R. I. I., \& den Hertog, J. (2011). Supporting First Grade Students Learning Number Facts up to 10 Using a Parrot Game. Indonesian Mathematical Society Journal on Mathematics Education, 2(2), 163-172.

Rusman. (2016). Model-model PembelajaranMengembangkanProfesionalisme Guru. Jakarta: PT Raja Grafindo Persada.

Sari. 2018. Pengaruh Penggunaan Media Batang Napier Terhadap Hasil Belajar Matematika di Kelas III Madrasah Ibtidaiyah Darul Huda Bandar Lampung. Universitas Islam Negeri Raden Intan Lampung.

Sugiyono. (2016). Metode Penelitian Kuantitatif, Kualitatif dan R\&D. Bandung: Alfabeta, CV.

Sundayana, R. (2015). Media dan Alat Peraga dalam Pembelajaran Matematika. Bandung: Alfabeta CV.

Suprijono, A. (2015). Cooperative Learning Teori dan Aplikasi PAIKEM.Yogtakarta: Pustaka Pelajar. 